\title{
BMJ Open Only eye study 2 (OnES 2): 'Am I going to be able to see when the patch comes off?' A qualitative study of patient experiences of undergoing high-stakes only eye surgery
}

\author{
Lee Jones (1D , ${ }^{1,2,3,4}$ Deanna J Taylor, ${ }^{1}$ Freda Sii, ${ }^{2,5}$ Imran Masood, ${ }^{2,6}$ \\ David P Crabb, ${ }^{1}$ Peter Shah ${ }^{2,4,5,7}$
}

To cite: Jones L, Taylor DJ, Sii F, et al. Only eye study 2 (OnES 2): 'Am I going to be able to see when the patch comes off?' A qualitative study of patient experiences of undergoing high-stakes only eye surgery. BMJ Open 2020;10:e038916. doi:10.1136/ bmjopen-2020-038916

- Prepublication history and additional materials for this paper is available online. To view these files, please visit the journal online (http://dx.doi. org/10.1136/bmjopen-2020038916).

Received 28 March 2020 Revised 14 August 2020 Accepted 30 September 2020

D Check for updates

C Author(s) (or their employer(s)) 2020. Re-use permitted under CC BY-NC. No commercial re-use. See rights and permissions. Published by BMJ.

For numbered affiliations see end of article.

Correspondence to

Lee Jones; lee.jones@city.ac.uk

\section{ABSTRACT}

Objectives Ocular surgery is a source of significant concern for many patients, especially in high-stakes circumstances. The purpose of this study was to explore patient experiences of undergoing surgery on their onlyseeing eye.

Design A qualitative investigation using semistructured face-to-face interviews. Transcripts were analysed using thematic analysis.

Setting Hospital eye service in the UK.

Participants Twelve participants with a diagnosis of glaucoma with worse eye visual acuity $<3 / 60 \pm$ endstage visual field loss. All participants had experience of undergoing surgery on their better-seeing (ie, 'only') eye. Results Data were coded into three key themes relating to (1) emotional impact of surgery, (2) burden of visual loss and (3) coping with surgery. Patients reported depressive symptoms at all stages of their surgical journey; concern about poor visual outcomes was a common feature. Only eye surgery imposes an emotional burden due to the uncertainty regarding individuals' ability to continue daily activities and maintaining social roles. Burden extended to the inconvenience of frequent hospital visits and difficulties with follow-up care. Participants' ability to cope effectively with surgery appeared to be linked to extent of support from healthcare professionals. Key areas in developing trust and support were an open and transparent dialogue between surgeons and patients, continuity of care, patient inclusion in decision-making, and observable empathy.

Conclusions The findings indicate a need for an enhanced model of care in only eye surgery to better target patient preferences and allay concerns inherent with these procedures.

\section{INTRODUCTION}

Surgery is undoubtedly a significant life event for patients across all fields of medicine. In ophthalmology, patients report challenges throughout their surgical journey. ${ }^{12}$ Surgical concerns are particularly pronounced among ophthalmology patients as eyesight is often regarded as the most valued sense, and loss of
Strengths and limitations of this study

- This is a unique study capturing in-depth qualitative data on patient perspectives of only eye surgery.

- Semistructured interviews provided the opportunity to gain knowledge about a wide range of aspects of this surgery.

- Recruitment was limited to two large urban hospital centres potentially limiting the generalisability of our findings.

- Purposive sampling was used which may have led to a bias.

which creates great trepidation. ${ }^{3}$ Yet, a large proportion of the population will not experience blindness in their lifetime, even those living with ophthalmic disease. ${ }^{45}$

Patients at an elevated risk of experiencing life-changing vision loss and blindness are those requiring surgery on their only-seeing eye. Despite the seemingly impressive safety profile of routine procedures like cataract surgery, ${ }^{6}$ and trabeculectomy for glaucoma, ${ }^{7}$ each year thousands of patients experience poor visual outcomes. ${ }^{8} 9$ For example, The National Ophthalmology Database in the UK showed that in 2018, over 3000 patients with cataract (with or without a copathology) were left with postoperative visual acuity (VA) of $6 / 60$ or worse. ${ }^{8}$ Moreover, serious complications with potential for irreversible vision loss occur in up to $5 \%$ of glaucoma surgical procedures. ${ }^{9}$ While loss of vision in an eye in a binocular patient may be devastating, the patient will likely retain functional vision, enabling driving and activities of daily living. However, loss of vision occurring in the better or 'only' eye is likely to have a devastating impact on patients' quality of life. ${ }^{1011}$ For example, vision in an only eye may make 
the difference between being able to drive legally or not, being able to work and being able to perform basic tasks of daily living independently.

Evidence suggests surgeons performing only eye surgery experience high levels of stress, as well as intense feelings of accountability when things go wrong. ${ }^{12}$ Currently, there is limited evidence relating to patient experiences of only eye surgery. A comprehensive evidence-based understanding of these high-stake procedures would help spotlight areas for improvement and promote a better surgical experience for patients. In addition, accurate knowledge of patient experiences may help improve clinical outcomes ${ }^{13}$; this is particularly important for only eye patients. The aim of this study, therefore, was to explore the real-world delivery of only eye surgery from the patient perspective.

\section{METHOD}

\section{Sampling and recruitment}

Individuals who met our criteria for being an only eye patient were invited to participate in a semistructured interview. As described in our previous work, ${ }^{12}$ the definition of an only eye was where significant loss of vision in this eye would be deemed life changing with profound impact on a patient's quality of life. VA in the fellow eye of $<3 / 60$ or worse \pm end-stage visual field loss was considered insufficient to maintain the patient's current independent lifestyle. All patients had a diagnosis of glaucoma and had undergone surgery on their only eye.

Participants were recruited from two secondary care centres in the UK. Purposive sampling was used where participants were invited to participate in the interview by their treating clinician while attending regular follow-up

\section{Table 1 Participant demographics}

\begin{tabular}{llll}
\hline Code & Sex & Diagnosis & $\begin{array}{l}\text { Most recent only eye } \\
\text { procedure }\end{array}$ \\
\hline M1 & Male & POAG & Phacoemulsification \\
F1 & Female & SOAG & Baerveldt Tube \\
F2 & Female & PCG & Trabeculectomy \\
M2 & Male & JOAG & Trabeculectomy \\
M3 & Male & POAG/SACG & Trabeculectomy \\
M4 & Male & JOAG & Trabeculectomy \\
M5 & Male & POAG & Phacoemulsification \\
F3 & Female & POAG & Trabeculectomy \\
F4 & Female & JOAG & Trabeculectomy \\
M6 & Male & SACG & Trabeculectomy \\
M7 & Male & SACG & Baerveldt Tube \\
F5 & Female & POAG & Baerveldt Tube \\
\hline
\end{tabular}

JOAG, juvenile open angle glaucoma; PCG, primary congenital glaucoma; POAG, primary open angle glaucoma; SACG, secondary angle closure glaucoma; SOAG, secondary open angle glaucoma.
Table 2 Interview topic guide

\section{Question}

purpose Item

Opening I am interested to hear about your experience as question an only eye patient. Can you say a bit about how this came about?

Main What were your first thoughts when you were

questions told you needed surgery? How did it make you feel?

What was most important to you before having the surgery?

What could have been done to improve your surgical experience?

What advice would you give to somebody in a similar circumstance to you?

Can you reflect back to any high points/low points?

If you could go back in time and replay events, how might it be different?

Closing Do you think there is anything else I could have question asked, or that you want to add?

visits for assessment of their eye health. Participant demographics are described in table 1. In total, 12 patients were approached, all of whom agreed to participate. We recruited patients from a range of ethnicities, eight selfreported as Caucasian, one as Afro Caribbean, two as Indian Asian and one as Bangladeshi.

\section{Data collection}

Written consent from all participants was obtained prior to conducting interviews. As per the guidelines by the WHO, an interview topic guide was devised and piloted prior to commencing the study. ${ }^{14}$ The interview topic guide (table 2) was developed following consultation with an advisory group of patients and healthcare professionals (HCPs). Interviews were audio recorded and conducted face-to-face by a male $\mathrm{PhD}$ researcher with a background in psychology and trained in qualitative research (LJ). Median (IQR) interview duration was 31 (22-37) min. Interviews were primarily carried out immediately after participants' follow-up consultation and took place in clinic rooms within the hospital eye service with participants' informal caregiver present. The researchers corresponded with participants via email and telephone during recruitment, and had met some participants previously through patient and public involvement events.

\section{Patient and public involvement}

The Only Eye Study (OnES) is a series of research projects investigating only eye surgery. This is the second output in the series and reports patient experiences. The outcomes of surgeon interviews have been described in a previous report. ${ }^{12}$ Patients were included in the study advisory group who helped to develop the interview topic guide. Following data analysis, a 'Bridging the Gap' event 
was hosted at Queen Elizabeth Hospital Birmingham to disseminate the research findings and conduct a membercheck exercise among stakeholders including surgeons, patients and carers.

\section{Data management and analysis}

Data were analysed using thematic analysis within a realist framework (ie, investigating the experiences and the reality of the participants). ${ }^{15}$ The codes and themes were developed using a semantic approach, whereby we considered the explicit content of the data at surface level. Familiarisation with the data was achieved by repeatedly reading the interview transcripts. ${ }^{16}$ Interviews were coded with manual and computer-based methods (NVivo V.11 (QSR International, Cambridge, Massachusetts, USA)). Data were analysed by one of the authors (LJ), and interpretation of the coding was discussed and finalised among the entire research team. Codes were not predefined, and an open, iterative process was used to develop codes from the data. Patterns of meaning in participants' responses were coded, and these patterns were further explored by grouping codes into similar categories both within and across interviews and finally by generating common and coherent themes best describing the data. ${ }^{15}$ The research team recognised that data saturation had occurred when no new themes were forthcoming in the later interviews. Member-checking was used, whereby the authors' interpretation of the data was shared and discussed with a sample of the participants to ensure trustworthiness and reliability of the findings. All participants were invited to a dissemination event at the end of the study where the member-check exercise took place. Of the 12 study participants, 10 participated in the member-check. No new themes were generated during this exercise and participants reported that the findings were accurate and representative of their experience. The study was designed and reported following the guidance of the Consolidated Criteria for Reporting Qualitative Research. ${ }^{17}$

\section{RESULTS}

Data were coded and developed into three key themes relating to only eye surgery: 'emotional impact of surgery'; 'burden of visual loss'; and 'coping with surgery'. Direct quotations taken from the interview transcripts are italicised and used to illustrate the chosen themes. All excerpts are annotated with a code given to the corresponding participant.

\section{Emotional impact of surgery}

'The whole world came crushing down around my shoulders; I went downhill very, very quickly.' (F1)

Participants described their strong negative emotional response to learning they require surgery on their only eye. A common theme across patient narratives was an overwhelming sense of fear and shock:

'I was so distressed I actually burst into tears. That's very unusual for me, I don't show when I'm upset' (F5).
'I walked out of there and I was absolutely devastated, completely and utterly devastated. I was majorly depressed and I didn't know how to get out of it... I felt lonely, I felt like I was the only person in the world that this had ever happened to. I didn't know what to do about it, I didn't know where to go, who to speak to. It was a horrendous time, absolutely horrendous time.' (F1).

'It was made worse by the fact I was going to university at the time, glaucoma was the last thing I was thinking about' (M6).

Along with the initial distress of learning of the necessity of surgery, a number of participants reported a sense of fear regarding the potential outcomes of surgery, as well as feelings of uncertainty as to what was happening:

'You do put your life in the surgeon's hands really. When I met my surgeon it was-I've got to be honest, I was terrified because I just had no idea where I was going and what was going to happen' (M4).

'This is my eye that does everything, I was nervous... I think more than anything it's the worry that if something goes wrong you've got nothing.' (M2).

'When you're at the first stages it's very scary because you don't know what's going on' (M7).

Fear of negative outcomes of surgery was particularly pronounced in patients who had a responsibility for others, where patients reported concerns about maintaining their caregiving role:

'My experience of going into an operation on an only eye, one way to describe it is absolutely petrifying. You don't know what's going to happen. That was very daunting because I'd got a very young little girl, and didn't know what was going to happen when I came out of it' (F1).

In some cases, participants had witnessed a family member losing vision to glaucoma, and this close involvement made them particularly fearful for themselves:

'My brother has got the same condition but he's gone blind, so that was a worrying factor for myself' (F2).

Although thoughts of undergoing surgery were worrisome, participants frequently reported the most concerning aspect was the postoperative period, where there were significant anxiety and panic immediately after the procedure regarding visual outcomes:

'I think the scariest bit was when you come out of surgery, where you come out of the theatre and you've got an eyepatch and it's scary...Between the operation and taking the eye patch off was pure panic. You think what am I going to see when I get this taken off - will I be able to see when they take the eye patch off' (F3). 
'I just feel very scared during the night [after surgery]. I wake up crying and I don't have anyone to say to that I'm scared' (F4).

'When I had my second surgery when I first woke up I couldn't see straightaway and I panicked like hell... You're lying there thinking, okay, I'll find out tomorrow morning when these bandages come off. I think that's where I've probably felt the most isolated, over that night' (F1).

'When I was having surgery on my good eye it was really scary. Because I can't see out of the other one, I was blind for a period of time afterwards which was pretty scary' (M4).

'I lay in bed for six weeks, I couldn't see the light above me and if I'd had a gun I'd have put a bullet in my head. I used to sit up and break my heart' (M7).

Many participants in this study had undergone a substantial number of surgical interventions. A common consensus was that 'failed' surgery (ie, where intraocular pressure was no longer stabilised) was emotionally challenging. One participant described their feeling of desperation and the hope that more could be done to save their vision:

'It started to reject. I panicked, really, really panicked. It was a tough time, it really really was. My surgeon said to me-I can't promise you anything but we'll give anything a go. At that point I was like just try anything; just do anything, anything you can do' (F1).

\section{Burden of visual loss}

'Eye problems and eye surgery is different to almost anything else because it is so overwhelming. Almost everything comes back to your eyesight. If you can't see a thing, how on Earth do you distract yourself to take away the fear?' (M4)

Living with restricted vision had an impact on participants' everyday life. Routine daily activities, such as reading and working, had become problematic due to deteriorating eyesight:

'I'm living in a world where increasingly I just cannot see. We sing in the church choir, but I can't see to read the music now... I can't read to my grandchildren. He snuggles up with a book, but I can't read to him. I have to say, oh, let's ask grandad' (F5).

'Vision in my left eye was bad enough that reading was becoming a problem, it was beginning to interfere with my job' (M1).

'I was an accounts clerk and my eyesight was failing at that point. They told me they were sorry but you're not seeing to do your job properly any more, we're going to have to let you go. So I lost my job as well' (F1).

'I can't drive anymore, which is a major thing for me' (M2).
Changes to daily life incurred a sense of grief among participants. In addition, vision loss affected significant life events, such as taking vacations:

'We went to Florida to see a rocket take off. I had my binoculars but I cried because I couldn't see it' (F1).

The burden of visual loss also extended to the inconvenience of frequent hospital visits for monitoring eye health, and the strain of relying on informal caregivers to attend clinics:

'I check in for my appointment, two hours later and I'm still waiting. There has to be a better system. I absolutely hate going, and now I have to go to two clinics. It will be the same story... What I really want to say is, I don't want to come in anymore because I don't like to be here... The visual fields, I hate them. You have to sit in front of a machine when you don't even know if it's working and you can't see any of the lights, all you get is a big black print out' (F5).

'It's expensive because I have to have time off work to attend appointments. There's massive financial implications because obviously I don't drive anymore, so (my wife) has to have the time off work' (M2).

A further burden was the often extensive treatment plans and repeated surgical interventions. The language participants used when describing their surgical experience gave some insight into how patients engage with the healthcare system. For example, surgery was described as a 'difficult journey' or a 'regime', giving a sense of the continuous and never-ending effort involved in trying to preserve their sight:

'Once you've had the surgery, it's not over... It is a journey of lots of different drops, a regime' (M3)

'I've had many operations, cataract surgery, trabeculectomies, and several bits of laser surgery. The journey has been difficult' (F3).

\section{Coping with surgery}

'The whole family just pulled together. They know how to sit and talk to me and get me believing in myself again'. (F1)

Many participants reported feelings of an inability to cope with the pressures of only eye surgery, primarily associated with concerns of further visual loss after surgery. It was clear that for some participants the gravity of the situation was so powerful that it led them to have suicidal thoughts:

'I'll be honest with you, if I lost my sight, you would have found me [dead]. I just couldn't cope... I meet people who have been remarkable by coping with it. I quite frankly just don't think I could' (M4).

'It's been very distressing. It's got to the point where because the deterioration since the surgery has been very significant-far more than it ever was beforehand-sometimes I just think, well, I'm not sure 
whether life's worth living now. I've got to the point where I have to really fight that thought' (F5).

Participants described an array of strategies and circumstances that have helped them to cope. Effective coping appeared to be heavily influenced by participants' relationship with their surgeon. Feelings of being cared for as an individual were important to many:

'The more they discuss with you what may happen, what your thoughts are about it, what they're going to attempt to do, it's a very big thing' (F1).

'My doctor, I say that he is a gift from God. He knows how to speak to patients and that's the main thing' (M5).

'They speak to me by my name, it's a personal thing. It's being made to feel you're a person, not a number on the list. (F3)

These comments highlighted the importance of empathy, and surgeons' ability to clearly and sensitively communicate about surgery. In contrast, participants who had frequently been under the care of multiple surgeons spoke negatively about occasions where they perceived a lack of empathy:

'My diagnosis was very cold and callous-it was jolly well insulting. Surgeons somehow need to bridge the intellectual gap and become empathetic towards their patients, especially in only eye surgery' (M4).

'The Consultant said there's nothing I can do for you, he said that's what glaucoma does to you. He said you're going to go blind and that's it' (F1).

Instances where participants felt they were not valued or included in the surgical decision-making process were detrimental to their ability to cope. For example, one participant commented on the failure of their Consultant to listen to and consider their perspective and priorities:

'They don't hear you. My Consultant, he doesn't hear me. I'm not blaming them for my condition. I am blaming them for forcing me to have surgery that has made it worse- a lot worse. They go blinkered towards lowering the eye pressure. Lowering the eye pressure is the Holy Grail, and they don't see anything else. Now I completely question the validity of doing the surgery in the first place' (F5).

Fostering a good relationship with their surgeon allowed participants to feel reassured and more trusting and confident with their care:

'I feel safe with the physician, but that's only because I've got a relationship with them. They've been there for me on the journey' (M7).

'I'm very happy with my care. I feel so safe that my doctor is looking after me' (F2).
'It's important you have confidence in your medical team...I would say that's one of the most important things' (M1).

Positive open dialogue between surgeons and patients was important to building a trusting relationship. Transparency about the surgical process allowed participants to better understand and make sense of what was happening, which helped them to cope with anxieties relating to surgery:

'My doctor explained we're doing this, this is what we're doing, this is where you're going next. The anaesthetist came round and said I need you to be very, very still, and explained why I had to do this' (F3).

'I've never been given any false promises. We've spoken about things in great depth...If anything were to go wrong and they tell me there's nothing else we can do, I'd believe them' (F1).

'You're entering into a contract and I wanted a lot of information. It depends on the individual but I was ravenous, I wanted to know what was going on and the consequences. I think if the surgeon can demonstrate to the individual that they really are on your side, you now have to trust this person.' (M3).

Other coping mechanisms came from informal support in both emotional and practical ways. Emotional support from family and friends during difficult times, as well as practical support, such as instilling eye drops, was considered to be of vital importance to well-being:

'The drops that you have to put in continually... I mean, I could never do that. You've got to have someone to put the drops in, because your drops are continuous' (F5).

'I was extremely fortunate that I've got a very good family around me. It is devastating and you need the support of your family' (F1).

Participants also described how they drew strength from religious community:

'I think, had I not got a strong faith and a very supportive church-if I had not had that, I'm absolutely certain that I'd have committed suicide. Absolutely certain I would have done that, because I can't see a future. I can't see any kind of future for myself, in a world where I've become almost an alien, really' (F5).

The role of dedicated peer support networks, such as charity groups and newsletters, was also discussed. However, the outcome of engaging with these services was not always positive. For example, one participant reported feeling alienated as the patient support material was not relevant to their experience of glaucoma and as an only eye patient:

'Even with the newsletter and leaflets, it's just a generic type of thing. It's not personal enough...If you 
don't seek it out yourself, there is no information' (M2).

Coping abilities appeared to be influenced by individuals' mental attitudes, such as maintaining an optimistic outlook:

'To come out of surgery with anything at all is better than what the future held for me. I think excited is the word, because I'm excited at what's going to happen' (F1).

'I wasn't fearful because I was confident that whatever happened, I made the right decision' (M1).

'You realise it's not a straight journey, it's variable, peaks and troughs, good days and bad days. I'm thankful for the good days and you get strength to cope in the bad days' (M3).

Finally, hospital staff taking steps to provide more individualised care provided a source of comfort. For example, extended visitation hours, particularly when preparing for surgery, helped participants to cope with surgical anxiety:

'It's nice to have someone I know with me until I get put to sleep, I think that's so important' (F4).

'My husband was allowed to stay with me until I actually went to theatre-it made me feel safe and comfortable' (F1).

\section{DISCUSSION}

Only eye patients will likely face exceptional challenges in their surgical journey. Decreased visual ability and the daunting prospect of invasive and potentially fruitless surgery, with a small but real possibility of total vision loss, present a difficult set of circumstances for both patients and surgeons. The purpose of this study was to generate new insights into only eye surgery through discussions with experts-by-experience, the patients themselves. Our findings highlighted several key areas for service improvements and opportunities to make the only eye surgery experience more patient centred.

Participants reported intense feelings of fear prior to undergoing only eye surgery. Preoperative fear was primarily associated with the potential for further visual loss and increased ocular morbidity. Preoperative fear is common among surgical patients, ${ }^{18} 19$ and elevated levels of fear and anxiety before surgery may increase surgical risks and affect health outcomes. ${ }^{20}$ Moreover, preoperative fear often leads to patients postponing surgery. ${ }^{21}$ As such, understanding and preventing fear should be a priority. Previous research suggests patients undergoing cataract surgery on their only eye report more preoperative fear than patients with binocular vision, citing further visual loss as the primary concern. ${ }^{22}$ The concept of prehabilitation has been introduced as a means of managing patients' uncertainties and aims to enhance patients' health state prior to surgery. Prehabilitation may be used to improve physical aspects of patients' lives, such as increasing exercise and nutrition, or may relate to mental wellbeing, such as psychological support to improve resilience. ${ }^{23}$ There is strong evidence that prehabilitation has a beneficial impact on surgical outcomes, including reduced hospital stay, postoperative pain and complications. ${ }^{24}$ Arguably, prehabilitation is already used in ophthalmology, for example, safeguarding the ocular surface with anti-inflammatory agents prior to cataract surgery. ${ }^{25}$ However, there is little evidence of targeted psychological support to help patients cope with surgical anxiety, as this is not yet an established element of care in ophthalmology. Identifying a feasible prehabilitation model for only eye patients, where concerns are effectively managed through psychological support, may provide a tangible aspect of care and help to allay some of the fears discussed in this study.

In addition to preoperative fear, many participants reported difficulties during postoperative care, and felt most vulnerable after surgery. Use of wound dressings to occlude the eye often accelerated concerns, due to causing uncertainty as to whether the surgery was successful. A common problem was the feeling of insufficient information from surgeons and HCPs regarding the surgical process, such as the outcome of surgery. Likewise, participants valued when aspects of their surgical journey were explained in more detail, such as what tests were being performed, where they would be going and why. This finding aligns with research on patients' dissatisfaction when they are not kept informed, ${ }^{26} 27$ and emphasises the importance of high-quality communication between patients and HCPs. Previous research in patients with glaucoma has highlighted a perceived lack of appropriate and relevant information provision from HCPs, although not directly relating to surgery. ${ }^{28}$ Indeed, it is necessary to consider the practicalities of delivering information to patients about surgery, such as what information should be provided, in what format should it be delivered and at what time point. ${ }^{29}$ Yet, many of the participants in our study explained how simple and brief feedback helped them to cope more successfully. Our findings emphasise the importance of effective patient communication about surgical processes and outcomes. We propose that prehabilitation may be a useful opportunity to provide guidance to patients about what to expect postoperatively. One clinically relevant outcome of better-targeted psychological support is the potential for reducing the use of antianxiety medications among fearful and nervous patients. ${ }^{30}$

It was clear that some participants had experienced negative encounters with HCPs on their surgical journey, often regarding a perceived lack of empathy. To be empathetic, HCPs need to understand what their patients are experiencing from their perspective and be mindful when discussing sensitive subjects, such as surgical intervention. Problems about doctor-patient 
communications are often attributed to a perceived lack of empathy, ${ }^{31}$ and a caring environment is the most influential factor when patients make judgements on their willingness to recommend hospitals. ${ }^{32}$ Participants in our study explained how, for example, 'being made to feel you're a person, not a number on the list' helped them to cope with surgery. How HCPs communicate with patients can have an impact on postsurgical outcomes, such as fewer functional limitations, ${ }^{33}$ and healthcare practices must recognise the important role empathy plays on patient rehabilitation in ophthalmology. ${ }^{34}$ Essentially, empathy is not immutable, ${ }^{35}$ and can be developed through simple interventions to improve care provision, or taught through dedicated skills training within medical school curricula and through postgraduate specialist training. ${ }^{36}$ There exists a number of provider communication frameworks designed to help elevate HCPs compassion and sustain distinctive cultures of caring, for example, the SPIKES protocol for delivering bad news and the Language of Caring library of applied empathy skills resources. ${ }^{37} 38$ This study is not the first to identify empathy as a crucial component of meeting patients' expectations in ophthalmology, ${ }^{39}$ and our findings further underline the importance of communication skills in ophthalmic medical education.

While some participants reported negative experiences, the majority of patients were happy with their care. A link was identified between positive experiences of surgery and trust in the care team. For example, participants gave details of forming a good relationship with their surgeon through honest and open dialogue, and appreciated when time was spent explaining surgery, leading patients to feel in 'safe hands'. However, surgeons cannot always successfully dedicate the necessary time to build good relationships with their patients. This is especially true in ophthalmology, which is consistently identified as the busiest outpatient specialty in the publicly funded National Health Service. ${ }^{40}$ This problem is accelerated by a shortfall in the number of ophthalmologists worldwide. ${ }^{41}$ One solution is to ensure all patients can access support nurses who have a pivotal role in patients' surgical care. Ophthalmic nurses are well placed to provide patients with sufficient information about their condition and treatment, while maintaining the interpersonal skills to offer reassurance and guidance. Greater recognition of the Eye Clinic Liaison Officer, whose role includes discussing information about eye conditions and providing emotional support, ${ }^{42}$ could be influential in fostering patient trust in healthcare institutions, and may have additional benefits to other findings from this study, such as reducing patients' fear of surgery.

Although the personal circumstances of our participants were highly varied, many demonstrated similarities in how they coped with surgery, such as the development of positive attitude traits. In particular, participants relied on maintaining an optimistic outlook about surgical outcomes. Previous research in patients with cataract has shown that those with higher outcome expectancies reported lower state anxiety levels, ${ }^{43}$ suggesting patients who are more hopeful and optimistic about surgery are more likely to cope effectively. There is convincing evidence for the benefit of cultivating adaptive personality traits when preparing for surgery, ${ }^{44}$ and our findings hint that a positive outlook can help patients cope better with only eye surgery. However, the relationship between expectations and outcomes is complex, and surgical expectations must be based in reality. For example, discussions around cancer surgery often do not address the patients' prognosis, such as the possibility of tumour recurrence and an estimation of life expectancy. ${ }^{45}$ When advising patients about surgery it is important that HCPs remain aware of their key role in striking a difficult balance between optimism and realism. This is especially true in only eye surgery, where any deviations from expected outcomes will be particularly challenging for patients.

Support from family and friends facilitated coping. Support came in the form of practical help, such as instilling eye drops after surgery, and emotional support to help cope with anxieties. It is common for patients with visual disability to rely on an informal caregiver, such as a spouse, partner, friends or family for support. ${ }^{46}$ Evidence suggests that informal caregivers of patients with advanced vision loss, such as only eye patients, are more likely to give higher scores on measures of strain and caregiver burden. ${ }^{47}$ As a result, caregivers for only eye patients may be most at risk of experiencing distress and disruption to lifestyle as a consequence of their informal role. It is important that eye care specialists who see only eye patients in their clinic are aware of potential caregiver strain, and provide support for both the caregiver and the patient. One solution is to have a multidisciplinary team approach to care, where counselling can be offered to patients and their caregivers to provide a more holistic approach when treating patients. Evidence shows that patients receiving psychological support in conjunction with surgical care are more likely to have better mental well-being, experience fewer problems following discharge and have a greater self-care ability. ${ }^{48}$ Finally, as with many patient populations, religious and spiritual beliefs are of high importance to individuals living with glaucoma. ${ }^{50} \mathrm{~A}$ mainstay of high-quality healthcare is to deliver culturally competent services, recognising factors such as religion and spirituality and the role they play in the needs of patients. Acknowledgement of the value of spirituality as an effective coping mechanism may help to promote trust when patients make treatment-related decision, ${ }^{51}$ while also eliciting an ethical and compassionate approach to healthcare in glaucoma.

The OnES is a series of research projects investigating only eye surgery. The first research output (OnES 1) identified recommendations on how to optimise patient safety from surgeons' perspectives, and the role of purpose-designed training fellowships and 
stress-reducing strategies in high-stakes procedures. ${ }^{12}$ In this study, we make recommendations for surgical care explored through the patient perspective. Based on our interview findings, we developed a model for optimal patient-centred care in only eye surgery (see online supplemental appendix 1). The model highlights patient preferences at key time points in the surgical journey. The sources of external support are key elements that may help to achieve patient preferences. It is the responsibility of HCPs to ascertain support networks available to their patients. When patient preferences are achieved, positive outcomes are more likely to be evident for all stakeholders including patients, their families, hospital services and those working in hospital ophthalmic care.

We recognise some limitations to our study. We recruited from only two large urban hospital centres, which may limit the extent to which our findings are generalisable. Notwithstanding this, our recruited sample was diverse consisting of participants of various ages, ethnicity, marital status, disease profile and treatment history, which permits some conceptual transference. The heterogeneity observed in our sample allows us to explore only eye surgery from a broad range of perspectives; however, closer investigation of how individual factors such as age and ethnicity affect surgical experiences is required. A further limitation was the presence of participants' informal caregiver during the interview may have incurred social desirability tendencies or a response bias. In addition, potential bias may be present from our use of purposive sampling. However, our aim was not to provide results that are generalisable to the population, but rather an in-depth exploration of the only eye surgery experience, and we are the first study group to do so. While the entire research team reviewed and discussed the interpretations of the findings, data analysis was primarily carried out by one author, and this is a limitation. Our results may also be influenced by recall bias; however, given the consistency in responses between participant interviews, we believe that the overall message of the report remains accurate.

This study open avenues for further research in the area of only eye surgery. Our findings indicate an unmet need for greater psychological support throughout the entire surgical journey for patients. Assessments into how best to support patients preparing for, and recovering from, only eye surgery would make an important contribution to knowledge on how to optimise care for this high-stakes patient cohort. This could be achieved through hospital outreach activities, such as patient-delivered workshops, to enable clinicians to understand patients' expectations of their care. Our sample consisted of patients with glaucoma who had undergone surgery on their only-seeing eye, thus our findings relate mostly to glaucoma-related and anterior segment surgery. It would be interesting for future research to assess patient experiences in other areas of ophthalmology, such as vitreoretinal surgery. Nevertheless, we speculate that the outcomes of this study will resonate with all ophthalmic surgical patients. There are currently no data regarding the cost implications of becoming an only eye patient, or loss of vision in an only eye. We hypothesise that health economic analysis to determine these figures will further underscore the importance of delivering effective and holistic healthcare to these patients.

Certain communities have differential disease burdens. In glaucoma, for example, several studies have associated socioeconomic deprivation with more advanced glaucoma severity at presentation, ${ }^{52}$ and these patients are more likely to match our definition of an only eye. ${ }^{4}$ It is necessary that clinicians understand the importance of deprivation, and the association of ethnicity, in patient health outcomes. This is particularly true for those based in healthcare centres in areas of high deprivation. The challenge is to reach and deliver equitable care to all patients in all communities.

To conclude, our findings indicate that more could be done to improve the surgical experience for only eye patients. Negative experiences in surgery included fear of the procedure, lack of empathy from care providers and poor information provision. Exploring these experiences using a qualitative approach has allowed us to gain a detailed understanding of aspects of only eye surgery which are most important to the patient. In addition, several suggestions for service improvement are made. This is pertinent given the wider trend in healthcare decision-making towards a more micro and personalised approach to service planning and delivery, ${ }^{53}$ where patient experience is becoming a fundamental measure to assess quality of care.

\section{Author affiliations \\ ${ }^{1}$ Division of Optometry and Visual Sciences, School of Health Sciences, City University of London, London, UK \\ ${ }^{2}$ Birmingham Institute for Glaucoma Research, Institute of Translational Medicine, Birmingham, UK \\ ${ }^{3} \mathrm{NIHR}$ Clinical Research Facility, Moorfields Eye Hospital NHS Foundation Trust, London, UK \\ ${ }^{4}$ Institute of Ophthalmology, University College London, London, UK \\ ${ }^{5}$ Department of Ophthalmology, University Hospitals Birmingham NHS Foundation Trust, Birmingham, UK \\ ${ }^{6}$ Birmingham and Midland Eye Centre, Birmingham, UK \\ ${ }^{7}$ Centre for Health and Social Care Improvement, University of Wolverhampton, Wolverhampton, UK}

\section{Twitter Lee Jones @crabblab}

Acknowledgements The authors would like to sincerely thank the advisory group who helped develop the interview topic guide, and the patients who provided their time and thoughts in the study interviews. We wish to dedicate this work to the memory of our friend Vinette Cross, whose guidance, support and enthusiasm during planning this study was invaluable; she is very much missed by all of us who were fortunate enough to have known and worked with her.

Contributors LJ performed the study design, data collection, data analysis and manuscript preparation. DJT, FS and IM performed the data analysis and manuscript critique. DPC performed the study design and manuscript critique. PS performed the study design, data analysis and manuscript critique. 
Funding The authors have not declared a specific grant for this research from any funding agency in the public, commercial or not-for-profit sectors.

Competing interests None declared.

Patient and public involvement Patients and/or the public were involved in the design, or conduct, or reporting, or dissemination plans of this research. Refer to the Methods section for further details.

\section{Patient consent for publication Not required.}

Ethics approval The study was approved by the London-Chelsea Research Ethics Committee (Ref: 17/L0/1664) and conformed to the tenants of the Declaration of Helsinki.

Provenance and peer review Not commissioned; externally peer reviewed. Data availability statement № data are available.

Open access This is an open access article distributed in accordance with the Creative Commons Attribution Non Commercial (CC BY-NC 4.0) license, which permits others to distribute, remix, adapt, build upon this work non-commercially, and license their derivative works on different terms, provided the original work is properly cited, appropriate credit is given, any changes made indicated, and the use is non-commercial. See: http://creativecommons.org/licenses/by-nc/4.0/.

\section{ORCID iD}

Lee Jones http://orcid.org/0000-0002-8030-1211

\section{REFERENCES}

1 Nijkamp MD, Ruiter RAC, Roeling M, et al. Factors related to fear in patients undergoing cataract surgery: a qualitative study focusing on factors associated with fear and reassurance among patients who need to undergo cataract surgery. Patient Educ Couns 2002;47:265-72

2 Cross V, Shah P, Glynn M, et al. ReGAE 5: can we improve the surgical journey for African-Caribbean patients undergoing glaucoma filtration surgery? some preliminary findings. Clin Ophthalmol 2009;3:1.

3 Enoch J, McDonald L, Jones L, et al. Evaluating whether sight is the most valued sense. JAMA Ophthalmol 2019

4 Saunders LJ, Russell RA, Kirwan JF, et al. Examining visual field loss in patients in glaucoma clinics during their predicted remaining lifetime. Invest Ophthalmol Vis Sci 2014;55:102-9.

5 Heijl A, Bengtsson B, Hyman L, et al. Natural history of open-angle glaucoma. Ophthalmology 2009;116:2271-6.

6 Stein JD. Serious adverse events after cataract surgery. Curr Opin Ophthalmol 2012;23:219.

7 Kirwan JF, Lockwood AJ, Shah P, et al. Trabeculectomy in the 21st century: a multicenter analysis. Ophthalmology 2013;120:2532-9.

8 The Royal College of Ophthalmologists. National ophthalmology database audit key findings summary, 2018. Available: https://www. nodaudit.org.uk/resources/publications-annual-report [Accessed 04 Nov 2019].

9 Gedde SJ, Herndon LW, Brandt JD, et al. Postoperative complications in the tube versus trabeculectomy (TVT) study during five years of follow-up. Am J Ophthalmol 2012;153:804-14.

10 Jones L, Bryan SR, Crabb DP. Gradually then suddenly? decline in vision-related quality of life as glaucoma worsens. J Ophthalmol 2017;2017:1621640.

11 Peters D, Heijl A, Brenner L, et al. Visual impairment and visionrelated quality of life in the early manifest glaucoma trial after 20 years of follow-up. Acta Ophthalmol 2015;93:745-52.

12 Jones L, Taylor DJ, Sii F, et al. The only eye study (OnES): a qualitative study of surgeon experiences of only eye surgery and recommendations for patient safety. BMJ Open 2019;9:e030068.

13 Doyle C, Lennox L, Bell D. A systematic review of evidence on the links between patient experience and clinical safety and effectiveness. BMJ Open 2013;3:e001570.

14 Kajornboon $\mathrm{AB}$. Using interviews as research instruments. E-J Res Teacher 2005;2:1-9.

15 Braun V, Clarke V. Using thematic analysis in psychology. Qual Res Psychol 2006;3:77-101.

16 Ritchie J, Lewis J, Nicholls CM, et al. Qualitative research practice: a guide for social science students and researchers. Sage, 2013.

17 Tong A, Sainsbury P, Craig J. Consolidated criteria for reporting qualitative research (COREQ): a 32-item checklist for interviews and focus groups. Int J Qual Health Care 2007;19:349-57.

18 D'Angelo C, Mirijello A, Leggio L, et al. State and trait anxiety and depression in patients with primary brain tumors before and after surgery: 1-year longitudinal study. J Neurosurg 2008;108:281-6.
19 Hoyer J, Eifert GH, Einsle F, et al. Heart-focused anxiety before and after cardiac surgery. J Psychosom Res 2008;64:291-7.

20 Frazier SK, Moser DK, Daley LK, et al. Critical care nurses' beliefs about and reported management of anxiety. Am J Crit Care 2003;12:19-27.

21 Phipps WJ, Monahan FD, Sands JK, et al. Medical-surgical nursing: health and illness perspectives. St. Louis: Mosby, 2003.

22 Marback RF, Espíndola RFde, Santhiago MRde, et al. Cataract surgery: emotional reactions of patients with monocular versus binocular vision. Rev Bras Oftalmol 2012;71:385-9.

23 Wynter-Blyth V, Moorthy K. Prehabilitation: preparing patients for surgery. BMJ 2017;358:j3702.

24 Santa Mina D, Clarke H, Ritvo P, et al. Effect of total-body prehabilitation on postoperative outcomes: a systematic review and meta-analysis. Physiotherapy 2014;100:196-207.

25 Movahedan A, Djalilian AR. Cataract surgery in the face of ocular surface disease. Curr Opin Ophthalmol 2012;23:68-72.

26 Keating NL, Green DC, Kao AC, et al. How are patients' specific ambulatory care experiences related to trust, satisfaction, and considering changing physicians? J Gen Intern Med 2002;17:29-39.

27 Tang PC, Newcomb C, Gorden S, et al. Meeting the information needs of patients: results from a patient focus group. Proceedings: a conference of the American medical informatics association. AMIA fall symposium, 1997: 672-6.

28 Glen FC, Crabb DP. Living with glaucoma: a qualitative study of functional implications and patients' coping behaviours. BMC Ophthalmol 2015;15:128.

29 Pager CK. Randomised controlled trial of preoperative information to improve satisfaction with cataract surgery. Br J Ophthalmol 2005;89:10-13.

30 Egan KJ, Ready LB, Nessly M, et al. Self-administration of midazolam for postoperative anxiety: a double blinded study. Pain 1992:49:3-8.

31 Saravanan B, Ranganathan E, Jenkinson LR. Lessons learnt from complaints by surgical patients. Clin Gover: Inter J 2007;12:155-8.

32 Otani K, Waterman B, Dunagan WC. Patient satisfaction: how patient health conditions influence their satisfaction. J Healthc Manag 2012;57:276-93

33 Kelley JM, Kraft-Todd G, Schapira L, et al. The influence of the patient-clinician relationship on healthcare outcomes: a systematic review and meta-analysis of randomized controlled trials. PLoS One 2014;9:e94207.

34 Mishra A, Browning D, Haviland MJ, et al. Communication skills training in ophthalmology: results of a needs assessment and pilot training program. J Surg Educ 2018;75:417-26.

35 Morse AR. Talking to patients about vision loss and rehabilitation. Arch Ophthalmol 2012;130:235-7.

36 Raper SE, Gupta M, Okusanya O, et al. Improving communication skills: a course for academic medical center surgery residents and faculty. J Surg Educ 2015;72:e202-11.

37 Baile WF, Buckman R, Lenzi R, et al. SPIKES-A six-step protocol for delivering bad news: application to the patient with cancer. Oncologist 2000;5:302-11.

38 Leebov W, Rogering C. The language of caring guide for physicians: communications essentials for patient-centered care. 2nd edn. Language of Caring, LLC, 2014.

39 Taylor DJ, Jones L, Binns AM, et al. 'You've got dry macular degeneration, end of story': a qualitative study into the experience of living with non-neovascular age-related macular degeneration. Eye 2019.

40 NHS Digital. Hospital outpatient activity 2018-19. Available: https:// digital.nhs.uk/data-and-information/publications/statistical/hospitaloutpatient-activity/2018-19 [Accessed 28 Jan 2020]

41 Resnikoff S, Felch W, Gauthier T-M, et al. The number of ophthalmologists in practice and training worldwide: a growing gap despite more than 200,000 practitioners. Br J Ophthalmol 2012;96:783-7.

42 Norwell C, Hiles C. Why every hospital should have an eye clinic liaison officer. Inter Congress Series 2005;1282:226-9.

43 Nijkamp MD, Kenens CA, Dijker AJM, et al. Determinants of surgery related anxiety in cataract patients. Br J Ophthalmol 2004;88:1310-4.

44 Sweeny K, Andrews SE. Should patients be optimistic about surgery? Resolving a conflicted literature. Health Psychol Rev 2017;11:374-86

45 Winner M, Wilson A, Ronnekleiv-Kelly S, et al. A singular hope: how the discussion around cancer surgery sometimes fails. Ann Surg Oncol 2017;24:31-7

46 Keeffe JE, Chou S-L, Lamoureux EL. The cost of care for people with impaired vision in Australia. Arch Ophthalmol 2009;127:1377-81.

47 McDonald L, Turnbull P, Chang L, et al. Taking the strain? Impact of glaucoma on patient's informal caregivers. Eye 2020;34:197-204. 
48 Tristaino V, Lantieri F, Tornago S, et al. Effectiveness of psychological support in patients undergoing primary total hip or knee arthroplasty: a controlled cohort study. J Orthop Traumatol 2016;17:137-47.

49 Cebeci F, Celik SS. Discharge training and counselling increase selfcare ability and reduce postdischarge problems in CABG patients. $J$ Clin Nurs 2008;17:412-20.

50 Magyar-Russell G, Fosarelli P, Taylor $\mathrm{H}$, et al. Ophthalmology patients' religious and spiritual beliefs: an opportunity to build trust in the patient-physician relationship. Arch Ophthalmol 2008; $126: 1262-5$
51 Wu P-X, Guo W-Y, Xia H-O, et al. Patients' experience of living with glaucoma: a phenomenological study. $J$ Adv Nurs 2011;67:800-10.

52 Lane M, Lane V, Abbott J, et al. Multiple deprivation, vision loss, and ophthalmic disease in adults: global perspectives. Surv Ophthalmol 2018;63:406-36.

53 Wiig S, Storm M, Aase K, et al. Investigating the use of patient involvement and patient experience in quality improvement in Norway: rhetoric or reality? BMC Health Serv Res 2013;13:206. 